\title{
Measurement for the Rehabilitation Efficacy of Aerobic Exercise of Male Elderly Patients with GPA based on Large-Scale Internet Data
}

\author{
Long Xiaodong, Tao Ganchen, Luo Hong*, Wang Yuefeng and Chen Yuanping \\ P.E. Department, Jinggangshan University, Ji'an Jiangxi, China \\ *Corresponding author: Luo Hong (henry219007@163.com)
}

\begin{abstract}
With the rapid development of medical informatization, the application of the Internet platform is popular in the health care industry. In this paper, we investigate the complementary rehabilitative effect of aerobics exercise of elderly chronic abacterial prostatitis (CAP), by using large-scale internet data. The objective grading scale (NIHCPSI) of chronic prostatitis symptoms is adopted to grade the two groups of patients before treatment, $30 \mathrm{~d}$ and $90 \mathrm{~d}$ of treatment, and at the same time measure the maximum flow rate(MFR)as well as the THF- $\alpha$ and IL-1 levels in seminal plasma. Result shows that When treatment of $30 d$ and $90 d$, the two groups NIH-CPSI grades, seminal plasma THF$\alpha$ and IL-1 levels are significantly lower than those before treatment, the observation group is significantly lower than the control group in the corresponding period, and the difference is with statistical significance $(P<0.01)$; When treatment of $30 d$ and $90 d$, the two groups' MFR are significantly higher than those before treatment, the observation group is significantly higher than the control group in the corresponding period, and the differences is statistically significant $(P<0.01)$. So that, taking aerobic exercise in addition to the conventional therapy can improve the curative effect and promote rehabilitation for the elderly CAP patients significantly.
\end{abstract}

Keywords: Internet platform, Elderly people; CAP; Aerobic exercise; Large-Scale data

\section{Introduction}

With the rapid development of medical information, the traditional hospital digital information system and electronic health records system has been far from meeting the requirements of mass medical data storage, analysis and data services. After the massive medical data generation and collection, how to store heterogeneous, massive, real-time, diverse data to achieve the rapid and accurate response of large-scale complex health data query, how to use data mining method, the massive medical data analysis, fast and effective for the user to provide valuable medical data services, to achieve the effect of disease prevention first, become a big data era medical field need to solve the problem. In medical data collection, with the regional medical information system, medical data center and data exchange platform construction, including structured and unstructured medical and health data will continue to expand and present a geometric level growth. At the same time, the generation and collection of medical data is no longer limited to the single environment of the hospital, which will include a variety of data sources from the family, private clinics, experimental testing center and other institutions. And with the development of the Internet of things technology and wearable devices, we can collect their own medical data at any time. Medical data is no longer the exclusive resources of a medical institution, it can provide data sharing and exchange in the region and the larger regional level until the national health information system. In medical data service, the current medical care system in China still has the problem of medical resource allocation, 
service cost, service cost, service quality and service efficiency. How to improve the efficiency and diversity of data services through large data processing and mining technology is an urgent problem to be solved. In the near future, we can through the mobile phone application directly to query different hospital records, prescription, inspection results, a list of charges; chronic diseases such as diabetes, blood sugar will be whenever and wherever possible self testing blood pressure data uploaded to the medical data center, data mining platform can automatically determine the dynamic development of the disease, and sent to the doctor remote diagnosis decision analysis; out of a lot of medical information from massive medical data mining, can be used to assist the grassroots doctors make diagnosis and treatment recommendations for patients; the patient's vital signs, medical imaging, diagnosis, prescription, operation and hospitalization bill the full cycle data will be carried out comprehensive analysis the track, changing the training data mining, to provide support for the subsequent design treatment; at the same time by collecting and analyzing large-scale medical and health data, can be used for screening, analysis and early warning epidemic of chronic diseases and epidemics, and for the public health management department of prevention and intervention plans and actions to provide advice and reference.

The proportion of older people in our country keeps rising and their health deserves the concern of the society [1]. Prostatitis is the frequently-occurring disease in older men which seriously affects the quality of daily life, and among which the CAP (chronic abacterial prostatitis) is the most common, accounting for more than $80 \%$ of all elderly prostatitis patients [2]. At present, the pathogenesis of CAP is still vague, and the diversity of clinical symptoms has brought major difficulties to the clinical diagnosis and treatment [3]. Studies show that the exercise of lifting and contracting anus can effectively improve the rehabilitation effect for CAP patients [4], but the application effect of exercise training in the auxiliary rehabilitation treatment of elderly CAP patients is still rarely reported at present. This study selected 62 cases of elderly CAP patients treated in the Urologic Surgery Clinic of our hospital, investigated and discussed the facilitation of the rehabilitation treatment effect of the aerobic exercise on the basis of the conventional therapy to those patients, providing references for developing clinical treatment plans.

\section{Literature Review}

Massive medical data are generated and collected, how to store massive, heterogeneous, real-time and diverse medical data to achieve the rapid and accurate response of large scale complex health data query. The real-time information and historical data can be used to provide medical care for medical staff. Meanwhile, the data mining theory and technology are applied to data mining.

In the face of complex structure and a wide range of medical data, the traditional data statistics methods are powerless; for the vast majority of medical data with non mathematical characteristics, non standardized representation of medical data, how to find a better data statistical analysis method has become the research hotspot in the field of data processing in the medical field. Data mining technology is to deal with the mass of data through the relevant algorithms, so as to achieve automatic information mode. Visible data mining technology can be used as an extension of the traditional data analysis method and supplement, to realize the complex medical data analysis and processing. The data mining technology based on cloud computing can be better on this basis to deal with massive, complex unstructured medical data computing needs. At present, data mining technology in the field of data processing and analysis in the field of medical and health has made many achievements, including the analysis of diabetes medical records, cancer risk factors, clinical data analysis of heart disease and health assessment model validation, etc. 
Zhu (2008) provides an overview of the data mining technology in the DNA sequence containing rules found the research status in, expounds the various data mining techniques, shows the DNA sequence by data mining technology research and give the data mining technology in the DNA sequence data columns need further research hot spot. Dreiseit (2006) pointed out important factors to affect the disease mortality; the data mining technology in the neural network technology, logistic regression method, decision tree technology three organic combinations, and make up for the use of a single method to lead to the analysis of the results is not accurate enough to say the power of the drawbacks. Sun (2010) research on the health management of time series data mining related issues were studied. Through the research of the existing health management system architecture and health data analysis and mining method, the data mining method of blood glucose monitoring in patients with diabetes is determined. The existing problems and the characteristics of the existing mining methods are deeply studied. Nahar (2009) pointed out the high mortality rate of cancer has not been controlled, hoping to extract important preventive factors for specific cancer types. In order to find out the factors, the authors established a data set (including breast cancer, bladder cancer, cervical cancer, prostate cancer, lung cancer, and skin cancer) based on a large number of literatures, and then used Apriori algorithm, Apriori Predictive algorithm and Tertius algorithm to analyze these specific cancer prevention factors. The experimental results show that the Apriori algorithm is the most effective in the detection of tumor risk factors. Palaniappan (2012) research a large number of data acquisitions and storage of medical care data, using data mining techniques, such as decision tree, Bias and neural network, the development of a smart heart disease prediction system (IHDPS). The experimental results show that each technique has its special features in the realization of medical information mining. IHDPS can answer some of the traditional decision support system cannot answer the question of medical complex questions. The system can predict the likelihood of heart disease by medical data such as age, sex, blood pressure and blood sugar.

With the steady growth of economy and the rapid development of modern information technology, more and more people pay more attention to their own health problems. Reasoning based on existing signs parameters their own health, do disease forecast the development of medical data services will be the future. Liu (2006) uses the data of China's health and Nutrition Survey to analyze the factors affecting the health of the elderly, and draw a series of conclusions through the analysis of the orderly logistic regression method. Among them, the factors that affect the health of their own age, marital status, education level, the objective body and mental health of the elderly, the most important factor is memory and life.Cheng (2009) establish a health condition evaluation system, and the evaluation system was expected to find out the trend of the development of the disease. According to the conclusions of the study, some disease prevention and health care measures are proposed, and some interventions to prevent the development of the disease. Yokoyama (2013) evaluate the performance of the esophageal and pharyngeal tumor health assessment model of the Japanese male population, 5 years of selective examination and testing, and the validity of the proposed esophageal and pharyngeal tumor health assessment model was determined. The experimental results show that the two kinds of health risk model HRA-F and HRA-G can better predict the health, and HRA-G is more sensitive than HRA-F. Karaolis (2014) use data mining system to evaluate the risk factors associated with cardiac events in patients with coronary heart disease. Cardiac events included acute myocardial infarction (MI), percutaneous coronary intervention (PCI), and coronary artery bypass grafting $(\mathrm{CABG})$. The experiment collected 369 cases, most of which were 
at least one risk event. The most important risk factors are gender, smoking, hypertension, diabetes, family history and so on.

The application of medical data is an important issue in the research of scholars at home and abroad. Because of medical data information island and medical data privacy protection issues, there is a large number of medical data sets of small, more than a sample data for a breakdown of the field of data or the subjective strong data based on the questionnaire survey, the credibility of the results obtained by using the information technology to be further research.

\section{Materials and Methods}

\subsection{General Information}

Select 62 cases of elderly patients (CAP) treated at the Urologic Surgery Clinic of the school affiliated hospital from July 2012 to December 2014. They all had clinical manifestations of different levels of altered urinary elimination, such as urgent urination, frequent urination, and urinary pain, combined with hypogastralgia of penis and scrotum, psychiatric symptoms such as insomnia and dysphoria, as well as sexual dysfunction [5]. PPMT was adopted to fix the pathogens; routine urine showed normal or there existed a small amount of white blood cells $(<10 / \mathrm{HP})$; prostate fluid lens examination showed: white blood cell count $\geq 10 / \mathrm{HP}$; lecithin body $\leq+++/$ HP[6]; bacterial growth was not found from prostate bacterial culture; excluding patients also with other disease of the genitourinary system. They are randomly divided into two groups: the observation group and the control group, each group has 31 cases [7]. The results of table 2 shows that: Before treatment, in the indicator of age, the difference value of the control group (65.51 \pm 3.52$)$ and the observation group $(65.12 \pm 3.22)$ is 0.39 year, and $(\mathrm{F}=0.204, \mathrm{P}=0.653$ $>0.05)$; in the indicator of height, the difference value of the control group (169.29 \pm 3.74$)$ and the observation group $(168.52 \pm 4.12)$ is $0.77 \mathrm{~cm}$, and $(\mathrm{F}=0.599, \mathrm{P}=0.442>0.05)$; in the indicator of weight, the difference value of the control group $(66.74 \pm 4.53)$ and the observation group $(65.41 \pm 4.55)$ is $1.33 \mathrm{~kg}$, and $(\mathrm{F}=1.312, \mathrm{P}=0.256>0.05)$; in the indicator of weight, the difference value of the control group $(66.74 \pm 4.53)$ and the observation group $(65.41 \pm 4.55)$ is $1.33 \mathrm{~kg}$, and $(\mathrm{F}=1.312, \mathrm{P}=0.256>0.05)$; in the indicator of weight, the difference value of the control group $(66.88 \pm 8.49)$ and the observation group $(68.20 \pm 8.66)$ is -1.32 times, and $(\mathrm{F}=1.491, \mathrm{P}=0.227>0.05)$. The differences of the two groups of patients in the average age, height, weight, and heart rate have no statistical significance $(\mathrm{P}>0.05)$, and have comparability [8].

Table 1. Comparison Table of Age, Height, Weight, and Heart Rate Levels before Treatment $(n=62)$

\begin{tabular}{cccccc}
\hline Item & Control group & $\begin{array}{c}\text { Observation } \\
\text { group }\end{array}$ & $\begin{array}{c}\text { Difference } \\
\text { value }\end{array}$ & $\begin{array}{c}\mathrm{F} \\
\text { value }\end{array}$ & $\begin{array}{c}\mathrm{P} \\
\text { value }\end{array}$ \\
\hline Age(year of age) & $65.51 \pm 3.52$ & $65.12 \pm 3.22$ & 0.39 & 0.204 & 0.653 \\
Height(cm) & $169.29 \pm 3.74$ & $168.52 \pm 4.12$ & 0.77 & 0.599 & 0.442 \\
Weight(KG) & $66.74 \pm 4.53$ & $65.41 \pm 4.55$ & 1.33 & 1.312 & 0.256 \\
Heart rate(times) & $66.88 \pm 8.49$ & $68.20 \pm 8.66$ & -1.32 & 1.491 & 0.227 \\
\hline
\end{tabular}

\subsection{Research Method}

3.2.1. Literature Method: According to the research purposes and contents of the paper, through the Jinggangshan university library, China Academic Journal Network, sports academic journals, Internet access to the relevant news reports, other disciplines academic journals (PHILOSOPHY, teaching, psychology, etc.), the system to retrieve, access, collect, collate the relevant papers and information on 
male prostatitis. To further understand the current situation and achievements of the previous research, the relevant professional books, to provide a theoretical basis for this study.

3.2.2. Method of Comparative Analysis: Comparison is a commonly used thinking method to understand, distinguish and confirm the similarity and difference among different things, so as to reveal the essence of things. This paper tries to understand the difference among the comprehensive ability to use computers of PE teachers through comparison.

3.2.3. Questionnaire Survey: Questionnaire survey is the main research method of this study, through the study of the empirical study of the variables of the empirical study of measurement indicators, and the empirical study through a large scale of the questionnaire to verify the research, for the construction of the elements of the reliability and validity of the guarantee. 70 questionnaires were issued, 66 were collected, 62 were valid questionnaires, the recovery rate was $94.29 \%$, the effective rate was $93.94 \%$. "Measurement method" is adopted by the expert questionnaire reliability, correlation coefficient $\mathrm{r}=; \mathrm{P}<0.01$, the reliability; validity of the structure and content of the test method, and that the expert opinions are basically the same, content structure is reasonable and effective.

3.2.4. Statistical Analysis: SPSS 16.0 was chosen to conduct statistical analysis. The measured data are represented with average number \pm standard deviation, and t-test is adopted for comparison between groups; the enumeration data are represented with percentage, and $\chi 2$ test is adopted for statistical analysis. $p>0.05$ represents that there is no significant difference or statistical significance, $\mathrm{P}<0.05$ represents that there is significant difference and it's with statistical significance. $\mathrm{P}<0.01$ represents that there is a very significant difference and it's with statistical significance.

3.2.5. Logical Reasoning Method: Logical analysis was carried out on the data statistical significance result using comparison, deduction, induction, analysis and reasoning. Related theoretical conclusions were drawn.

3.2.6. Experimental Method: Give conventional therapy to the patients of the control group, specifically: Oral cefixime $0.1 \mathrm{~g}$, twice a day, $1 \sim 2$ weeks in total; prostate massage once a week, 7 times in total; hot bath for $25 \sim 30 \mathrm{~min}$ every night, take terazosin $3 \mathrm{mg}$ before sleep. Give indomethacin to patients having obvious pain, give diazepam to patients with too much mental tension; collect prostatic fluid of patients every two weeks to conduct bacterial culture and drug susceptibility test. The above course of treatment last $90 \mathrm{~d}$. The patients of the observation group take sport exercise on the basis of the conventional therapy same as the control group, and they are guided by the exercise rehabilitation coach who has received professional training to choose appropriate modes of exercise according to the personal conditions of patients. Table 2 shows that: 3 people jogging, accounting for $9.68 \%$, exercise frequency in one week is 5-7times, 30-50mins each time; 6 people Tai $\mathrm{Ji}$, accounting for $19.35 \%$, exercise frequency in one week is 6-7 times, 30-60mins each time; 6 people croquet, accounting for $19.35 \%$, exercise frequency in one week is 4-7 times, 100-120mins each time; 13 people fast walking, accounting for $41.94 \%$, exercise frequency in one week is 6-10 times, 40-60mins each time; among which, the 3 jogging people accounts for $9.68 \%$, with the exercise frequency of 6-7 times/week, and lasts 80-120mins each time. Their exercise load and intensity are basically similar or equal. We have different requirements for different patients, so the main standard is that they have slight fatigue. 
Table 2. Table of Aerobic Exercise Item Distribution of the Observation Group ( $n=31)$

\begin{tabular}{ccccc}
\hline Indicator & $\begin{array}{c}\text { Number } \\
\text { of people }\end{array}$ & Proportion $(\%)$ & $\begin{array}{c}\text { Exercise times per } \\
\text { week }\end{array}$ & $\begin{array}{c}\text { Time of each time of } \\
\text { exercise(minutes) }\end{array}$ \\
\hline jogging & 3 & 9.68 & $5-7$ times & $30-50$ \\
Tai Ji & 6 & 19.35 & $6-7$ times & $30-60$ \\
croquet & 6 & 19.35 & $4-7$ times & $100-120$ \\
Fast walking & 13 & 41.94 & $6-10$ times & $40-60$ \\
Square dance & 3 & 9.68 & $6-7$ times & $80-120$ \\
\hline
\end{tabular}

\subsection{Observational Indicator}

The objective grating scale (NIH-CPSI) for chronic prostatitis symptoms made by the US national institute of health $(\mathrm{NIH})$ was adopted in the grading of the urination condition, pain discomfort, and quality of life of the two groups' patients before treatment, 30d of treatment and $90 \mathrm{~d}$ of treatment [9]. At the meantime, measure the maximum flow rate (MFR) when the patient's urine volume $>160 \sim 200 \mathrm{ml}$, and measure the THF- $\alpha$ and IL-1 levels in the seminal plasma of patients of two groups. Evaluate the curative effect of two groups of patients after $90 \mathrm{~d}$ of treatment according to Clinical disease diagnosis and curative effect judgment standard (Science and technology literature press). Among which, the cured: Subjective symptoms disappear entirely, the grades of prostatitis-related symptoms return to normal, the bacteria detection of prostatic fluid shows negative [10]; improved: Subjective symptoms and the grades of prostatitisrelated symptoms are significantly improved, the bacteria detection of prostatic fluid shows negative; ineffective: Subjective symptoms and the grades of prostatitis-related symptoms are not improved or become worse, the bacteria detection of prostatic fluid shows positive. In this study, we consider the cured and the improved as the effective to count the total effective rate.

\section{Empirical Analysis}

\subsection{Comparative Analysis of NIH-CPSI Grade,MFR,Seminal Plasma THF- $a$ And IL-1 Levels}

The result of table 3 shows: Before treatment, in the indicator of "grade of urinating condition", the difference value of the control group(6.21 \pm 0.59$)$ and the observation group $(6.35 \pm 0.66)$ is -0.14 , and $(\mathrm{F}=0.832, \mathrm{P}=0.365>0.05)$; in the indicator of "grade of pain and discomfort", the difference value of the control group(13.96 \pm 2.01$)$ and the observation group (13.61 \pm 2.60$)$ is 0.35 , and $(\mathrm{F}=0.361, \mathrm{P}=0.550>0.05)$; in the indicator of "grade of living quality", the difference value of the control group $(8.01 \pm 0.88)$ and the observation group $(8.11 \pm 0.90)$ is -0.10 , and $(\mathrm{F}=0.183, \mathrm{P}=0.670>0.05)$; in the indicator of " overall grade", the difference value of the control group(28.18 \pm 4.87$)$ and the observation group $(28.07 \pm 4.18)$ is 0.11 , and $(\mathrm{F}=0.186, \mathrm{P}=0.640>0.05)$; in the indicator of "MFR $(\mathrm{ml} / \mathrm{s})$ ", the difference value of the control group $(16.53 \pm 0.59)$ and the observation group $(16.37 \pm 0.53)$ is 0.16 , and $(\mathrm{F}=1.249, \mathrm{P}=0.268>0.05)$; in the indicator of "THF$\alpha(\mathrm{ng} / \mathrm{ml})$ ", the difference value of the control group $(0.50 \pm 0.04)$ and the observation $\operatorname{group}(0.51 \pm 0.05)$ is -0.01 , and $(\mathrm{F}=0.770, \mathrm{P}=0.384>0.05)$; in the indicator of " $\mathrm{IL}-1(\mathrm{ng} / \mathrm{ml})$ ", the difference value of the control group $(0.65 \pm 0.06)$ and the observation group $(0.68 \pm 0.08)$ is -0.04 , and $(\mathrm{F}=3.041, \mathrm{P}=0.086>0.05)$; as we can see, before treatment, the $\mathrm{P}$ values of the two groups of patients in the CPSI grade, MFR, the THF- $\alpha$ and IL-1 levels in seminal plasma all higher than 0.05, thus the difference among them has no statistical significance. It provides reference for further studies and has comparability. 


\section{Table 3. CPSI Grades, MFR, Seminal Plasma THF- $\alpha$ and IL-1 Level Indicators} Contrast of the Control Group and Observation Groups before Treatment $(n=62)$

\begin{tabular}{cccccc}
\hline Item & $\begin{array}{c}\text { Control } \\
\text { group }\end{array}$ & $\begin{array}{c}\text { Observation } \\
\text { group }\end{array}$ & $\begin{array}{c}\text { Difference } \\
\text { value }\end{array}$ & $\begin{array}{c}\mathrm{F} \\
\text { value }\end{array}$ & $\begin{array}{c}\mathrm{P} \\
\text { value }\end{array}$ \\
\hline Grade of urinating condition & $6.21 \pm 0.59$ & $6.35 \pm 0.66$ & -0.14 & 0.832 & 0.365 \\
Grade of pain and discomfort & $13.96 \pm 2.01$ & $13.61 \pm 2.60$ & 0.35 & 0.361 & 0.550 \\
Grade of living quality & $8.01 \pm 0.88$ & $8.11 \pm 0.90$ & -0.10 & 0.183 & 0.670 \\
Overall grade & $28.18 \pm 4.87$ & $28.07 \pm 4.18$ & 0.11 & 0.186 & 0.640 \\
MFR $(\mathrm{ml} / \mathrm{s})$ & $16.53 \pm 0.59$ & $16.37 \pm 0.53$ & 0.16 & 1.249 & 0.268 \\
THF- $\alpha(\mathrm{ng} / \mathrm{ml})$ & $0.50 \pm 0.04$ & $0.51 \pm 0.05$ & -0.01 & 0.770 & 0.384 \\
IL-1 $(\mathrm{ng} / \mathrm{ml})$ & $0.65 \pm 0.06$ & $0.68 \pm 0.08$ & -0.04 & 3.041 & 0.086 \\
\hline
\end{tabular}

The result of table 4 shows that: after $30 \mathrm{~d}$ of treatment, in the indicator of "grade of urinating condition", the difference value of the control group $(5.55 \pm 1.11)$ and the observation group $(4.51 \pm 1.40)$ is 1.04 , and $(\mathrm{F}=10.420, \mathrm{P}=0.002<0.05)$; in the indicator of "grade of pain and discomfort", the difference value of the control group (12.67 \pm 2.41$)$ and the observation group $(10.61 \pm 2.89)$ is 2.06 , and $(\mathrm{F}=9.302, \mathrm{P}=0.003<0.05)$; in the indicator of "grade of living quality", the difference value of the control group (7.40 \pm 1.22$)$ and the observation group $(6.30 \pm 1.74)$ is 1.10 , and $(\mathrm{F}=8.253, \mathrm{P}=0.006<0.05)$; in the indicator of " overall grade", the difference value of the control group $(25.62 \pm 5.01)$ and the observation group $(21.42 \pm 5.78)$ is 4.20 , and $(\mathrm{F}=9.325, \mathrm{P}=0.003<0.05)$; in the indicator of "MFR ( $\mathrm{ml} / \mathrm{s})$ ", the difference value of the control group $(17.51 \pm 1.87)$ and the observation group $(19.53 \pm 2.80)$ is -2.02 , and $(\mathrm{F}=11.123, \mathrm{P}=0.001<0.05)$; in the indicator of "THF- $\alpha(\mathrm{ng} / \mathrm{ml})$ ", the difference value of the control group $(0.45 \pm 0.05)$ and the observation group $(0.41 \pm 0.08)$ is 0.04 , and $(\mathrm{F}=8.194, \mathrm{P}=0.006<0.05)$; in the indicator of "IL-1 $(\mathrm{ng} / \mathrm{ml})$ ", the difference value of the control group $(0.57 \pm 0.05)$ and the observation group $(0.52 \pm 0.07)$ is 0.05 , and $(\mathrm{F}=13.980, \mathrm{P}=0.000<0.05)$.

After $90 \mathrm{~d}$ of treatment, in the indicator of "grade of urinating condition", the difference value of the control group (4.77 \pm 1.07$)$ and the observation group (3.82 \pm 0.87$)$ is 0.95 , and $(\mathrm{F}=14.437, \mathrm{P}=0.000<0.05)$; in the indicator of "grade of pain and discomfort", the difference value of the control group $(11.22 \pm 2.41)$ and the observation group $(9.22 \pm 1.14)$ is 2.00 , and $(\mathrm{F}=17.315, \mathrm{P}=0.000<0.05)$; in the indicator of "grade of living quality", the difference value of the control group $(6.96 \pm 1.08)$ and the observation group $(5.88 \pm 1.21)$ is 1.08 , and $(\mathrm{F}=13.606, \mathrm{P}=0.00,0<0.05)$; in the indicator of " overall grade", the difference value of the control group (22.95 \pm 4.56$)$ and the observation group (18.92 \pm 3.31$)$ is 4.03 , and $(\mathrm{F}=15.117, \mathrm{P}=0.000<0.05)$; in the indicator of "MFR $(\mathrm{ml} / \mathrm{s})$ ", the difference value of the control group $(18.60 \pm 2.22)$ and the observation group $(21.07 \pm 2.35)$ is -2.47 , and $(\mathrm{F}=18.006, \mathrm{P}=0.000<0.05)$; in the indicator of "THF- $\alpha(\mathrm{ng} / \mathrm{ml})$ ", the difference value of the control group $(0.40 \pm 0.07)$ and the observation group $(0.34 \pm 0.04)$ is 0.06 , and $(\mathrm{F}=15.275, \mathrm{P}=0.000<0.05)$; in the indicator of "IL-1 $(\mathrm{ng} / \mathrm{ml})$ ", the difference value of the control group $(0.53 \pm 0.07)$ and the observation group $(0.44 \pm 0.10)$ is 0.09 , and $(\mathrm{F}=15.363, \mathrm{P}=0.000<0.05)$.

After treatment of 30d and 90d, the CPSI grade, MFR, the THF- $\alpha$ and IL-1 levels in seminal plasma of the two groups of patients are all significantly higher than before treatment, and the observation group is higher than the control group in the same period very significantly and the difference between them has statistical significance $(\mathrm{P}<0.01)$. 


\section{Table 4. CPSI Grades, MFR, Seminal Plasma THF- $\alpha$ and IL-1 Level Indicators Contrast of the Control Group and Observation Groups after Treatment $(n=62)$}

\begin{tabular}{|c|c|c|c|c|c|}
\hline \multirow[t]{2}{*}{ Indicator } & \multicolumn{5}{|c|}{ Treatment 30d } \\
\hline & Control group & $\begin{array}{l}\text { Observation } \\
\text { group }\end{array}$ & $\begin{array}{c}\text { Differe } \\
\text { nce } \\
\text { value }\end{array}$ & F value & $\begin{array}{c}\mathrm{P} \\
\text { value }\end{array}$ \\
\hline Grade of urinating condition & $5.55 \pm 1.11$ & $4.51 \pm 1.40$ & 1.04 & 10.420 & 0.002 \\
\hline Grade of pain and discomfort & $12.67 \pm 2.41$ & $10.61 \pm 2.89$ & 2.06 & 9.302 & 0.003 \\
\hline Grade of living quality & $7.40 \pm 1.22$ & $6.30 \pm 1.74$ & 1.10 & 8.253 & 0.006 \\
\hline Overall grade & $25.62 \pm 5.01$ & $21.42 \pm 5.78$ & 4.20 & 9.325 & 0.003 \\
\hline $\operatorname{MFR}(\mathrm{ml} / \mathrm{s})$ & $17.51 \pm 1.87$ & $19.53 \pm 2.80$ & -2.02 & 11.123 & 0.001 \\
\hline THF- $\alpha(\mathrm{ng} / \mathrm{ml})$ & $0.45 \pm 0.05$ & $0.41 \pm 0.08$ & 0.04 & 8.194 & 0.006 \\
\hline \multirow[t]{2}{*}{$\mathrm{IL}-1(\mathrm{ng} / \mathrm{ml})$} & $0.57 \pm 0.05$ & $0.52 \pm 0.07$ & 0.05 & 13.980 & 0.000 \\
\hline & \multicolumn{5}{|c|}{ Treatment 90d } \\
\hline Grade of urinating condition & $4.77 \pm 1.07$ & $3.82 \pm 0.87$ & 0.95 & 14.437 & 0.000 \\
\hline Grade of pain and discomfort & $11.22 \pm 2.41$ & $9.22 \pm 1.14$ & 2.00 & 17.315 & 0.000 \\
\hline Grade of living quality & $6.96 \pm 1.08$ & $5.88 \pm 1.21$ & 1.08 & 13.606 & 0.000 \\
\hline Overall grade & $22.95 \pm 4.56$ & $18.92 \pm 3.31$ & 4.03 & 15.117 & 0.000 \\
\hline $\operatorname{MFR}(\mathrm{ml} / \mathrm{s})$ & $18.60 \pm 2.22$ & $21.07 \pm 2.35$ & -2.47 & 18.006 & 0.000 \\
\hline THF- $\alpha(\mathrm{ng} / \mathrm{ml})$ & $0.40 \pm 0.07$ & $0.34 \pm 0.04$ & 0.06 & 15.275 & 0.000 \\
\hline $\mathrm{IL}-1(\mathrm{ng} / \mathrm{ml})$ & $0.53 \pm 0.07$ & $0.44 \pm 0.10$ & 0.09 & 15.353 & 0.000 \\
\hline
\end{tabular}

\subsection{Comparative Analysis of NIH-CPSI Grade,MFR,Seminal Plasma THF-a And IL-1 Levels}

The result of table 5 shows that: after $30 \mathrm{~d}$ of treatment, in the indicator of "cured", the difference value between the control group ( 8 people) and the observation group (12 people) is -4 ; in the indicator of "improved", the difference value between the control group (8people) and the observation group ( 6 people) is 2 ; in the indicator of "ineffective", the difference value between the control group (15 people) and the observation group (13 people) is 2 ; in the indicator of "total effective rate (\%)", the difference value between the control group (51.61\%) and the observation group (58.06\%) is $-16.13 \%$; after treatment of $90 \mathrm{~d}$, the total effective rate of the observation group is significantly higher than that of the control group, and the difference has statistical significance $(\mathrm{P}<0.05)$.

Table 5. Comparison of Therapeutic Effects of Two Groups after $30 \mathrm{~d}$ of Treatment $(\mathrm{n}=62)$

\begin{tabular}{cccccc}
\hline Group & $\mathrm{n}$ & Cured & Improved & Ineffective & Total effective rate $(\%)$ \\
\hline Control group & 31 & 8 & 8 & 15 & 51.61 \\
Observation group & 31 & 12 & 6 & 13 & 58.06 \\
Difference value & 0 & -4 & 2 & 2 & -6.45 \\
P value & & $*$ & & & $*$ \\
\hline
\end{tabular}

Note: * means $\mathrm{P}<0.05$

The result of table 4 shows that: after $90 \mathrm{~d}$ of treatment, in the indicator of "cured", the difference value between the control group (16 people) and the observation group (19 people) is -3 ; in the indicator of "improved", the difference value between the control group ( 6 people) and the observation group ( 9 people) is 3 ; in the indicator of "ineffective", the difference value between the control group ( 9 people) and the observation group (3 people) is 6; in the indicator of "total effective rate (\%)", the difference value between the control group (70.97\%) and the 
observation group $(87.10 \%)$ is $-16.13 \%$; after treatment of $90 \mathrm{~d}$, the total effective rate of the observation group is significantly higher than that of the control group, and the difference has statistical significance $(\mathrm{P}<0.05)$.

Table 6. Comparison of Therapeutic Effects of Two Groups after $90 \mathrm{~d}$ of Treatment $(n=62)$

\begin{tabular}{cccccc}
\hline Group & $\mathrm{n}$ & Cured & Improved & Ineffective & Total effective rate (\%) \\
\hline Control group & 31 & 16 & 6 & 9 & 70.97 \\
Observation group & 31 & 19 & 9 & 3 & 87.10 \\
Difference value & 0 & -3 & -3 & 6 & -16.13 \\
& & $*$ & $*$ & $*$ & $*$ \\
\hline
\end{tabular}

Note: * means $\mathrm{P}<0.05$

\section{Conclusions}

CAP has complicated aetiological agents and various clinical symptoms. At present, the methods of diagnose and treatment for this disease is relatively less and the curative effects of most therapies are not ideal [11]. Some researchers think that the judgement of the therapeutic effect of this disease should be based on whether the clinical symptoms disappear, the pathogenic bacteria test shows negative and the conventional cytologic examination of the prostatic fluid shows normal [12]. While studies of recent years show that, the white blood cell count in the prostatic fluid has no significant correlation with the symptoms. CPSI grade can evaluate the prostatitis symptoms effectively. The cytokines also play important roles in the illness. The levels of THF- $\mathrm{a}$ and IL-1 in the seminal plasma of the patient are positively associated with CPSI grade [13-14]. Therefore, in this study, we take CPSI grade、MFR 、 seminal plasma THF-a and IL-1 levels as observational indicators to evaluate the application effect of exercise training in the adjuvant therapy of elderly CAP.

This study shows that after treatment of $30 \mathrm{~d}$ and $90 \mathrm{~d}$, the CPSI grade、 seminal plasma THF-a and IL-1 levels of two groups are significantly lower than those before experiment, while MFR is significantly higher than that before experiment. This suggests that the two kinds of therapeutic schedules can both achieve satisfying effect. After treatment of $30 \mathrm{~d}$ and $90 \mathrm{~d}$, the CPSI grade、 seminal plasma THF-a and IL-1 levels of the observation group are significantly lower than those of the control group, which reminds the elderly CAP patients to do exercises to strengthen physique, improve immunity and reduce the inflammatory cytokine levels in the seminal plasma. The MFR of the observation group is significantly higher than that of the control group, which may because that the exercise improves the muscle strength around the anus, abdominal and pelvic cavity [15], and the coordination function of autonomic nerves, reducing the closing pressure of the urethra and the passivity of IPUR. After treatment $90 \mathrm{~d}$, the overall effective rate of the observation group is significantly higher than that of the control group, which suggests that taking adjuvant aerobic exercise on the basis of conventional therapy can improve the curative effect and promote the somatic function for the elderly CAP patients significantly. The relatively younger elderly CAP patients can choose jogging; patients with some sports foundation can play Tai $\mathrm{Ji}$, croquet or square dance; and the advanced aged patients or patients with poor physical fitness can choose fast walking. The above exercises all include the movements of extrusion and torsion of abdomen, lifting of anus and so on, which can rub the prostate, dredge prostate ducts, and promote the secretion of prostate fluid, reducing the pain and 
inflammation of the elderly CAP patients [16]. But there are still $13.90 \%$ patients whose curative effects are not very well, which suggests that the therapeutic schedule should be further improved.

In conclusion, Taking scientific aerobic exercise on the basis of the conventional therapy can improve the curative effect and promote rehabilitation for the elderly CAP patients significantly, and it's worth clinical application and promotion.

\section{References}

[1] W.Wenchao, "The Development and Revelation of American Elderly Education”,Journal of Henan Normal University, Vol.2,(2011),pp.1-9

[2] Z.Zhengrong, and L.Chaochao, "The Investigation and Analysis of the Pain and Urination of Patients with Chronic Prostatitis",International Journal of Urinary System, Vol.2, (2014), pp.153-157.

[3] Z.Zhiyong, "The Diagnosis, Treatment and New Progress of Gastrointestinal Stromal Tumor", Journal of Shandong University, (2011),pp.1-9

[4] X.Zhounan, "Clinical Curative Observation of Shaofuzhuyu Granules Combined with Anus-lifting Exercise to the Type prostatitis ". Chinese Sexology, Vol.6, (2011),pp. 33-35.

[5] L.Yu, "Clinical Curative Analysis of Xueshuantong Injection in the Treatment of Cerebral Infarction”.Medical Frontier, Vol.6,(2014), pp. 260-261

[6] L.Xiaobin, and Y.Yang,"160 Cases of Laboratory Diagnosis and Clinical Application of Chronic Prostatitis",Journal of Laboratory Medicine and Clinic, Vol.18,(2010) , pp. 2009-2010.

[7] C.Ziyu, "Clinical Observation of the Treatment of Periodontitis with the Internal and External Use of Jiaweiqingwei Powder”,Journal of Doctor \& Pharmacy (academic), Vol.5,(2012),pp. 586-587.

[8] C. Jianfeng,'The Multi-center, Randomized and Double-blind Clinical Study of the Secondary Prevention of Ischemic Stroke of the Traditional Chinese Medicines that Benefit Vital Energy, Activate Blood Circulation and Nourish Yin', Journal of Chengdu University of TCM, Vol.3,(2011),pp. 1-7

[9] Z.Qidong, “The Diagnosis and Treatment of prostatitis',Anhui Medical Journal, Vol.5, (2006), pp. 437438.

[10] Z.Liquan, and Z.Shengtian, "Curative Effect Observation of the Treatment of Chronic Prostatitis with a1A Receptor Blocking', Journal of Taishan Medical College, Vol.7, (2008), pp. 492-494.

[11] M.Tiejun, and Z.Wei, " Effect Observation of Treatment of Elderly Prostatitis by Circumcision Combined Drug Therapy”, Chinese Journal of Gerontology, Vol.17, (2013),pp. 4265-4266.

[12] S.Yan, "Clinical Observation of Combined Treatment of Traditional Chinese Medicine and Western Medicine of Acute Prostatitis", Chinese Emergency Medicine in TCM, Vol.4, (2014),pp. 708-709.

[13] L.Shunhong, "Curative Effect Observation of the Treatment of Prostatitis with Medicine Combined Pelvic Floor Muscle Exercise”,Chinese Journal of Medicine, Vol.10,(2013),pp. 54-55.

[14] X.Guangyu, and M.Qinrong,"Curative effect Observation of the Treatment of Type-IIIA Prostatitis with Roxithromycin Sustained Release Capsules combined Tamsulosin”, China Pharmacist, Vol.8,(2014), pp. $1362-1364$.

[15] L. Huayun, "Complementary Rehabilitative Effect of Exercise Training on Patients with Chronic Nonbacterial Prostatitis" ,Chinese Journal of Sports Medicine, Vol.12,(2011).pp. 1120-1123.

[16] L.Jiangbin, "The Clinical Observation and Pharmacokinetic Study of the Treatment of Chronic Prostatitis with Prostatic Embolus", Journal of Beijing University of TCM, (2001), pp. 33-37 